\title{
Pengaruh Agregat Kasar Ringan Buatan dari Tanah Diatomae pada Beton Ringan Struktural terhadap Nilai Kuat Tarik Belah
}

\author{
Siti Ghufrani Ajrina ${ }^{1}$ Taufiq Saidi ${ }^{2}$ Muttaqin $^{3}$ \\ 1,2,3 Jurusan Teknik Sipil, Universitas Syiah Kuala, Banda Aceh 23111, Indonesia \\ *Corresponding Author, email: sitighufrani.ajrina@gmail.com
}

\begin{abstract}
The development of structural lightweight concrete in the world of construction is very rapid. Lightweight structural concrete has the advantage of reducing the dead load of a construction and having good strength. Lightweight concrete can be obtained by using lightweight aggregates, which is the use of diatomae soil as coarse aggregates in concrete. The purpose of this study was to determine the split tensile strength of lightweight concrete. The benefit of this research is to produce structural lightweight concrete made from diatomae soil, so that it is expected to be an alternative in utilizing natural resources. Diatomae soil as an artificial light coarse aggregate was made with two variations which are aggregate from diatomae soil only (KBD variation) and aggregate combined from diatomae soil mixture and $5 \%$ sawdust smaller than 0.6 $\mathrm{mm}$ (KBDSG variation). Each variation is made by making small circles measuring 5-20 mm. Then the aggregate was heated at $100^{\circ} \mathrm{C}$ for 24 hours and burned in the furnace for 3 days. The results of the study showed the largest average split tensile strength value in the KBD variation of $3.558 \mathrm{MPa}$ and the lowest value of $2.913 \mathrm{MPa}$ with an average of $3.237 \mathrm{MPa}$. In the KBDSG variation of lightweight concrete, the largest split tensile strength was obtained at $3.258 \mathrm{MPa}$, and the smallest split tensile strength was $2.757 \mathrm{MPa}$ with an average of $2.992 \mathrm{MPa}$.
\end{abstract}

Keywords: Structural Lightweight Concrete, Light Coarse Aggregate, Diatomae Soil, Split Tensile Strength

\begin{abstract}
Abstrak
Perkembangan beton ringan struktural dalam dunia konstruksi sangat pesat. Beton ringan struktural memiliki keuntungan dapat mengurangi beban mati suatu konstruksi dan memiliki kekuatan yang baik. Beton ringan dapat diperoleh dengan cara menggunakan agregat ringan sebagai pengganti agregat normal, salah satunya adalah penggunaan tanah diatomae sebagai agregat kasar dalam beton. Tujuan dari penelitian ini untuk mengetahui kuat tarik belah dari beton ringan. Manfaat dari penelitian ini adalah menghasilkan beton ringan struktural yang terbuat dari tanah diatomae, sehingga diharapkan akan menjadi alternatif dalam memanfaatkan sumber daya alam. Tanah diatomae sebagai agregat kasar ringan buatan dibuat dengan dua variasi, yaitu agregat dari tanah diatomae saja (variasi KBD) dan agregat dari campuran tanah diatomae dan $5 \%$ serbuk gergaji berukuran lebih kecil 0,6 mm (variasi KBDSG). Setiap variasi dibuat dengan cara dibuat bulatan-bulatan kecil berukuran 5-20 mm. Kemudian agregat dioven pada suhu $100{ }^{\circ} \mathrm{C}$ selama 24 jam dan dibakar di tungku pembakaran selama 3 hari. Hasil dari penelitian diperoleh nilai kuat tarik belah rata terbesar pada variasi KBD sebesar 3,558 MPa dan nilai terendah sebesar 2,913 MPa dengan rata-rata 3,237 MPa. Pada beton ringan variasi KBDSG, kuat tarik belah terbesar didapatkan sebesar 3,258 MPa, dan kuat tarik belah terkecil sebesar 2,757 MPa dengan rata-rata 2,992 MPa.
\end{abstract}

Kata Kunci : Beton Ringan Struktural, Agregat Kasar Ringan, Tanah Diatomae, Kuat Tarik Belah

\section{Pendahuluan}

Perkembangan beton ringan struktural dalam dunia konstruksi saat ini sangat pesat. Hal ini dikarenakan beton ringan memiliki keuntungan, yaitu dapat mengurangi beban mati yang diterima pada suatu konstruksi. Beton ringan dapat dibuat dengan berbagai cara, salah satunya dengan penggunaan agregat ringan sebagai penyusunnya. Agregat ringan dapat diperoleh langsung dari alam atau diperoleh melalui proses pengolahan terlebih dahulu, seperti agregat yang berasal dari tanah diatomae.

Tanah diatomae merupakan bahan alami yang sangat banyak ditemukan di Indonesia. Berdasarkan data Dinas Pertambangan dan Energi Provinsi Aceh tahun 2012, di Kabupaten Aceh Besar sebaran tanah diatomae banyak terdapat di Desa Lampanah dengan estimasi 40.353.700.00 ton [1]. Oleh karena itu, pemanfaatan tanah diatomae sebagai agregat ringan pada beton dapat menjadi alternatif dalam membuat beton ringan

Tujuan dari penelitian ini adalah untuk mengetahui nilai kuat tarik belah dari beton ringan struktural dengan menggunakan agregat kasar ringan buatan yang berasal dari tanah diatomae. Penelitian ini bermanfaat untuk menghasilkan beton ringan struktural yang terbuat dari tanah diatomae, sehingga diharapkan akan menjadi alternatif dalam memanfaatkan sumber daya alam yang ada.

Beton ringan struktural dengan agregat kasar dari tanah diatomae pada penelitian ini dilakukan di Laboratorium Konstruksi dan Bahan Bangunan, Fakultas Teknik, Universitas Syiah Kuala. Tanah diatomae diperoleh dari Desa Lampanah, Seulimum, Aceh Besar digunakan sebagai agregat kasar ringan buatan dengan dua variasi, yaitu agregat dengan tanah diatomae saja dan agregat dengan campuran tanah diatomae dan 5\% serbuk gergaji.

Penelitian ini menggunakan benda uji silinder berukuran 10 x $20 \mathrm{~cm}$ sebanyak 5 benda uji untuk setiap variasi dengan Fas 0,45. Penelitian dimulai dengan pembuatan agregat ringan buatan, perencanaan campuran beton ringan, pengecoran dan perawatan beton ringan hingga pengujian kuat tarik belah beton pada umur 28 hari.

\section{Tinjauan Kepustakaan}




\subsection{Beton Ringan}

Beton ringan merupakan beton terkandung agregat ringan didalamnya dan mempunyai berat isi maksimum $1900 \mathrm{~kg} / \mathrm{m}^{3}$ [2]. Beton dengan berat isi tidak lebih dari $1850 \mathrm{~kg} / \mathrm{m}^{3}$ dan sudah memenuhi ketentuan kuat tekan dan kuat tarik belah serta mengandung agregat ringan didalamnya dinamakan sebagai beton ringan struktural [3].

\subsection{Agregat Ringan}

Komponen yang berpengaruh pada kualitas beton adalah agregat. Hal ini dikarenakan agregat sebagai pengisi beton menempati sebagian besar dari berat campuran beton. Menurut Nugraha dan Antoni [4] volume pada beton ditempati oleh agregat sebesar $70-75 \%$. Berat isi pada agregat halus ringan adalah sebesar $1120 \mathrm{~kg} / \mathrm{m}^{3}$, $880 \mathrm{~kg} / \mathrm{m}^{3}$ pada agregat kasar, dan $1040 \mathrm{~kg} / \mathrm{m}^{3}$ pada campuran agregat kasar dan halus [5].

\subsection{Tanah Diatomae}

Batuan dengan kandungan silika dinamakan sebagai tanah diatomae. Tanah diatomae dapat diperoleh dari fosil tumbuhan air dan ganggang bersel satu. Tanah diatomae terdiri dari $86 \%$ silika, 5\% natrium, 3\% magnesium, dan $2 \%$ besi [6]. Tanah diatomae dicirikan sebagai struktur mikro yang sangat berpori (80-90\% pori), kepadatan rendah, luas permukaan tinggi, kapasitas adsorbsi besar, konduktivitas termal rendah, dan suhu leleh tinggi [7].

\subsection{Pengaruh Suhu Pembakaran Agregat Diatomae terhadap Kuat Tekan Beton \\ Posi,dkk [8] melakukan penelitian mengenai kuat} tekan beton ringan yang mengandung agregat dari tanah diatomae yang tekalsinasi , Hasil yang diproleh adalah pada agregat halus dan agregat berukuan sedang akan mempunyai sifat pozzolan pada suhu pembakaran $600^{\circ} \mathrm{C}$. Sedangkan agregat kasar akan mempunyai kekuatan yang baik pada suhu pembakaran $1000{ }^{\circ} \mathrm{C}$ sebesar $12,9 \mathrm{MPa}$.

\subsection{Pengaruh Campuran Serbuk Gergaji pada Agregat Ringan Diatomae}

Fragoulis, dkk [9] melakukan penelitian tentang karakteristik agregat ringan dengan tanah diatomae yang berasal dari Yunani. Penelitian ini mencampur tanah diatomae dengan $2 \%, 3,5 \%$, dan $5 \%$ serbuk gergaji dengan berukuran minimal $1 \mathrm{~mm}$. Campuran kemudian dibuat bulatan-bulatan kecil berukuran 5-20 mm. Kemudian dioven selama 24 jam dengan suhu $100{ }^{\circ} \mathrm{C}$. Bulatanbulatan kecil tersebut kemudian dibakar pada suhu $1100{ }^{\circ} \mathrm{C}$ selama 12-15 menit. . Berdasarkan pengujian kerapatan dan kuat fraktur agregat didapatkan hasil kerapatan agregat yang rendah, yaitu berkisar antara $0,55-0,79 \mathrm{~g} / \mathrm{cm}^{3}$ dan memiliki kekuatan agregat yang cukup baik pada agreagt dengan komposisi tanah diatomae dan 5\% serbuk gergaji dengan kuat fraktur sebesar 2029 g. Berdasarkan hasil penelitian laboratorium, Kekuatan dan kepadatan pada lightweight aggregates (LWA) penelitian ini memiliki sifat yang sama seperti LWA komersial dari Jerman dan Denmark.

\section{6}

\section{Kuat Tarik Belah}

Nilai kuat tarik belah beton diperoleh dari hasil pembebanan maksimum benda uji silinder yang diletakkan horizontal pada permukaan mesin uji tekan [10]. Perhitungan kuat tarik belah berdasarkan SNI 2491-2014 dapat dihitung dengan Persamaan 1

$$
\mathrm{f}_{\mathrm{ct}}=\frac{2 P}{\pi L D}
$$

dimana:

$\mathrm{f}_{\mathrm{ct}} \quad=$ Kuat tarik-belah $(\mathrm{MPa})$

$\mathrm{P}=$ Beban uji maksimum (beban belah/hancur) $(\mathrm{N})$ yang ditunjukkan mesin uji tekan

$\mathrm{L} \quad=$ Panjang beban uji $(\mathrm{mm})$

$\mathrm{D}=$ Diamter benda uji $(\mathrm{mm})$

Persyaratan nlai kuat tekan dan kuat tarik belah rata-rata pada beton struktural [11] dapat dilihat pada Tabel 1

Tabel 1 Persyaratan Kuat Tekan dan Kuat Tarik Belah Rata-Rata untuk Beton Ringan.

\begin{tabular}{ccc}
$\begin{array}{c}\text { Berat isi kering 28 } \\
\text { hari, maksimum } \\
(\mathrm{kg} / \mathrm{cm} 3)\end{array}$ & $\begin{array}{c}\text { Kuat tarik belah } \\
\text { (tidak langsung) } \\
\text { rata-rata (MPa) }\end{array}$ & $\begin{array}{c}\text { Kuat tekan rata-rata, } \\
\text { 28 hari, minimum } \\
(\mathrm{MPa})\end{array}$ \\
\hline \multicolumn{3}{c}{ Semua Agregat } \\
\hline 1760 & 2,2 \\
\hline 1680 & 2,1 & 28 \\
\hline 1600 & 2,0 & 21 \\
\hline 1840 & Agregat ringan dan pasir \\
\hline 1760 & 2,3 \\
\hline 1680 & 2,1 & 28 \\
\hline
\end{tabular}

Sumber : SNI 2461-2014

\subsection{Hubungan Kuat Tarik Belah terhadap Kuat} Tekan Beton Ringan

Menurut Dipohusodo [12] Perkiraan nilai kuat tarik belah beton normal berkisar 9\%-15\% dari kuat tekan beton. Menurut Park dan Paulay [13] nilai kuat tarik belah terhadap kuat tekan pada beton umum sekitar atau lebih kecil $20 \%$.

Menurut Bogas dan Nogueira [14] banyak peneliti (misalnya Zhang dan Gjorv, 1991; Hoff, 1992; Haque, dkk, 2004; Wallman, 2006) menemukan bahwa beton ringan (LWAC) mempunyai kuat tarik yang lebih kecil dari beton normal (NWC) untuk kuat tekan yang sama. Sedangkan menurut Bamforth dan Nolan (2000) yang dikutip oleh Bogas dan Nogueira [14], melaporkan bahwa beton ringan memiliki kuat tarik belah lebih besar dari beton normal. Hal ini terjadi pada beton ringan yang memiliki jumlah pasta yang besar, ikatan antara agregat dan pasta yang baik, dan bentuk agregat yang lebih bulat.

Adapun rumus hubungan antara kuat tekan terhadap kuat tarik belah disajikan pada Tabel 2.

Tabel 2 Rumus hubungan antara kuat tekan dan kuat tarik belah beton ringan struktural [14]

\begin{tabular}{lll}
\hline Referensi & Hubungan Antara $\mathrm{f}_{\mathrm{cm}}$ dan $\mathrm{f}_{\mathrm{ctm}}{ }^{\mathrm{a}}$ & Keterangan \\
\hline FIP (1983) & $\mathrm{f}_{\mathrm{ctm}, \mathrm{r}}=\mathrm{c.} \mathrm{f}_{\mathrm{cm}, \mathrm{cub}}{ }^{2 / 3}[\mathrm{MPa}]$ & $0,46<\mathrm{c}<0,55 ;$ \\
& $20<\mathrm{f}_{\mathrm{cm}}<60$ \\
& $\mathrm{MPa}$ \\
\hline \multirow{2}{*}{$\mathrm{f}_{\mathrm{ctm}, \mathrm{sp}}=0,23 \mathrm{f}_{\mathrm{cm}, \mathrm{cub}}{ }^{2 / 3}[\mathrm{MPa}]$} & $20<\mathrm{f}_{\mathrm{cm}}<60$ \\
& $\mathrm{MPa}$ \\
\hline
\end{tabular}




\begin{tabular}{|c|c|c|}
\hline $\begin{array}{l}\text { Fib } 8 \\
(2000)\end{array}$ & $\begin{array}{c}\mathrm{f}_{\mathrm{ctm}}=\mathrm{c} \cdot \mathrm{f}_{\mathrm{ck}}{ }^{2 / 3}(0,4+0,6 \rho / 2200) \\
{[\mathrm{MPa}]}\end{array}$ & $\begin{array}{c}\mathrm{c}=0,3(\mathrm{CEB}, \\
1990) \text { or } 0,26 \\
(\mathrm{CEB} 228, \\
1995)\end{array}$ \\
\hline $\begin{array}{l}\text { ACI } 318 \\
(2009)\end{array}$ & $\mathrm{f}_{\mathrm{ctm}, \mathrm{sp}}=\mathrm{a} \cdot \mathrm{f}_{\mathrm{cm}, \mathrm{cyl}}{ }^{1 / 2}[\mathrm{MPa}]$ & $\begin{array}{c}a=0,42 \\
(\text { ALWC) or } \\
0,47 \text { (LWAC) }\end{array}$ \\
\hline $\begin{array}{l}\text { ACI } 318 \\
(2009)\end{array}$ & $\mathrm{f}_{\mathrm{ctm}, \mathrm{r}}=\mathrm{b} \cdot \mathrm{f}_{\mathrm{cm}, \mathrm{cyl}}{ }^{1 / 2}[\mathrm{MPa}]$ & $\begin{array}{c}\mathrm{b}=0,42 \\
\text { (ALWC) or } \\
0,53 \text { (LWAC) }\end{array}$ \\
\hline \multirow[t]{2}{*}{$\begin{array}{l}\text { EN 1992-1 } \\
(2004)\end{array}$} & $\begin{array}{c}\mathrm{f}_{\mathrm{ctm}}=0,3\left(\mathrm{f}_{\mathrm{ck}}\right)^{2 / 3} \cdot(0,4+0,6 \rho / 2200) \\
{[\mathrm{MPa}]}\end{array}$ & $\begin{array}{c}20<\mathrm{f}_{\text {ck,cyl }}<50 \\
\mathrm{MPa}\end{array}$ \\
\hline & $\begin{array}{c}\mathrm{f}_{\mathrm{ctm}}= \\
2,12 \cdot \operatorname{In}\left(1+\mathrm{f}_{\mathrm{cm}} / 10\right) \cdot(0,4+0,6 \rho / 2200) \\
{[\mathrm{MPa}]}\end{array}$ & $\begin{array}{c}50<\mathrm{f}_{\mathrm{ck}, \mathrm{cyl}}<80 \\
\mathrm{MPa}\end{array}$ \\
\hline $\begin{array}{l}\text { NS } 3473 \\
(1992)\end{array}$ & $\begin{array}{c}\mathrm{f}_{\mathrm{ctm}}= \\
\mathrm{f}_{\mathrm{ctm}, \mathrm{NWC}}(0,15+0,85 / 2200)[\mathrm{MPa}]\end{array}$ & $\begin{array}{l}\text { Reduction of } \\
15 \% \text { in } \\
\text { ALWAC }\end{array}$ \\
\hline $\begin{array}{l}\text { Berge } \\
(1973)\end{array}$ & $\begin{array}{c}\mathrm{f}_{\mathrm{ctm}, \mathrm{sp}}= \\
\mathrm{f}_{\mathrm{cm}, \mathrm{cub}}{ }^{1 / 3}(0,07+0,93 / 2400)[\mathrm{MPa}]\end{array}$ & \\
\hline \multirow{2}{*}{$\begin{array}{l}\text { Zhang and } \\
\text { Gjorv } \\
\text { (1991) }\end{array}$} & $\mathrm{f}_{\mathrm{ctm}, \mathrm{r}}=0,73 \mathrm{f}_{\mathrm{cm}, \mathrm{cub}}{ }^{1 / 2}[\mathrm{MPa}]$ & \multirow{2}{*}{$\begin{array}{l}50<\mathrm{f}_{\mathrm{cm}}<100 \\
(\text { water curing) }\end{array}$} \\
\hline & $\mathrm{f}_{\mathrm{ctm}, \mathrm{sp}}=0,23 \mathrm{f}_{\mathrm{cm}, \mathrm{cub}}{ }^{2 / 3}[\mathrm{MPa}]$ & \\
\hline $\begin{array}{c}\text { Morales } \\
(1990)\end{array}$ & $\begin{array}{c}\mathrm{f}_{\mathrm{ctm}, \mathrm{r}}=0,36 \mathrm{f}_{\mathrm{cm}, \mathrm{cyl}} \mathrm{l}^{1 / 2}[\mathrm{MPa}] \\
\mathrm{f}_{\mathrm{cttm}, \mathrm{sp}}=0,42 \mathrm{f}_{\mathrm{cm}, \mathrm{cyl}}{ }^{1 / 2}[\mathrm{MPa}]\end{array}$ & air curing \\
\hline Uijl et al. & $\mathrm{f}_{\mathrm{ctm}, \mathrm{sp}}=0,24 \mathrm{f}_{\mathrm{cm}, \mathrm{cyl}}{ }^{2 / 3}[\mathrm{MPa}]$ & water curing \\
\hline \multirow{2}{*}{$\begin{array}{l}\text { Swamy } \\
\text { and } \\
\text { Lambert } \\
(1983)\end{array}$} & $\mathrm{f}_{\mathrm{ctm}, \mathrm{r}}=0,9 \mathrm{f}_{\mathrm{cm}, \mathrm{cub}}{ }^{0.43}[\mathrm{MPa}]$ & \multirow[b]{2}{*}{$\begin{array}{l}20<\mathrm{f}_{\mathrm{cm}}<60 \\
(\text { water curing) }\end{array}$} \\
\hline & $\mathrm{f}_{\mathrm{ctm}, \mathrm{sp}}=0,3 \mathrm{f}_{\mathrm{cm}, \mathrm{cub}}{ }^{0.64}[\mathrm{MPa}]$ & \\
\hline
\end{tabular}

Sumber : Bogas dan Nogueira (2014)

${ }^{\mathrm{a}} \mathrm{f}_{\mathrm{ctm}}, \mathrm{f}_{\mathrm{ctm}, \mathrm{r}}, \mathrm{f}_{\mathrm{ctm}, \mathrm{sp}}=$ Rata-rata kuat tarik aksial, kuat lentur, dan kuat tarik belah

${ }^{\mathrm{a}}-\mathrm{f}_{\mathrm{ck}}, \mathrm{f}_{\mathrm{cm}, \mathrm{cyl}}=$ Karakteristik dan kuat tekan rata-rata beton silinder $\phi 150$ × $300 \mathrm{~mm}$

${ }^{\mathrm{a}}-\mathrm{f}_{\mathrm{cm}, \mathrm{cub}} \rho=$ Rata-rata kuat tekan beton kubus $150 \times 150$ $\mathrm{mm}$ dan berat volume kering beton

\section{Metodologi Penelitian}

\subsection{Rancangan Penelitian}

Pengujian kuat tarik belah pada penelitian menggunakan spesimen berbentuk silinder ukuran $10 \mathrm{~cm}$ x $20 \mathrm{~cm}$ dan diuji pada umur 28 hari dengan Faktor air semen (FAS) sebesar 0,45. Agregat kasar ringan dibuat dari tanah diatomae yang diproses terlebih dahulu. Sedangkan agregat halus yang digunakan berasal dari pasir alam. Proporsi agregat kasar ringan buatan harus memenuhi SNI 2461:2014 dan pada agregat halus harus memenuhi PBI 1971.

Agregat kasar ringan dibuat dalam 2 variasi, yaitu agregat kasar dengan komposisi tanah diatomae sepenuhnya, dan agregat kasar dengan campuran tanah diatomae dan $5 \%$ serbuk gergaji. Sehingga, benda uji beton ringan juga dibuat menjadi dua variasi, yaitu beton ringan dengan agregat kasar dari komposisi tanah diatomae sepenuhnya (KBD), dan beton ringan dengan agregat kasar dari komposisi campuran tanah diatomae dan 5\% serbuk gergaji (KBDSG). Setiap variasi benda uji berjumlah 5 benda uji. Adapun variasi benda uji dapat dilihat pada Tabel 3

Tabel 3 Variasi dan Jumlah Benda uji pada Pengujian Kuat Tarik Belah Beton.

$\begin{array}{lllll}\text { Pengujian } & \text { Nama } & \text { Uji }\end{array}$

\begin{tabular}{llcc} 
& & \multicolumn{2}{c}{ ISSN 2685-0605 } \\
\hline $\begin{array}{l}\text { Kuat tarik } \\
\text { belah beton } \\
\text { ringan } \\
\text { struktural }\end{array}$ & $\mathrm{KBD}_{11-15}$ & 0,45 & 5 \\
\cline { 2 - 4 } & $\mathrm{KBDSG}_{21-25}$ & 0,45 & 5
\end{tabular}

Keterangan:

1. Digit ke-1 pada subscript nama benda uji merupakan variasi agregat kasar; dan digit ke-2 merupakan nomor benda uji.

\subsection{Prosedur Penelitian}

Prosedur penelitian ini meliputi studi literatur, pekerjaan persiapan, pembuatan agregat ringan, perencanaan proporsi campuran beton (mix design), pembuatan benda uji, perawatan benda uji, pengujian kuat tarik belah beton, dan pengolahan data hasil pengujian.

\subsubsection{Pekerjaan Persiapan}

Pekerjaan persiapaan meliputi pengadaan peralatan dan material. Peralatan yang digunakan selama penelitian ini sudah tersedia di Laboratorium Konstruksi dan Bahan Universitas Syiah Kuala. Material pada penelitian ini menggunakan agregat kasar tanah diatomae dari Desa Lampanah, Seulimum, Aceh Besar.

\subsubsection{Pembuatan Agregat Kasar Ringan}

Agregat ringan buatan dalam penelitian ini dibuat dengan cara menghancurkan tanah diatomae menjadi bongkahan-bongkahan kecil, kemudian dioven pada suhu $100^{\circ} \mathrm{C}$ selama 24 jam dan dilanjutkan dengan menghancurkan bongkahan-bongkahan tersebut menggunakan mesin los angeles agar butiran-butiran yang dihasilkan lolos saringan no.200. Setelah itu, butiranbutiran tanah diatomae dibentuk dengan dua variasi. Pada variasi pertama(variasi KBD), butiran tanah diatomae dicampurkan air sebanyak $50 \%$ dari total berat butiran hingga berbentuk adonan. Adonan kemudian dibentuk menjadi bulatan-bulatan kecil berukuran 5-20 mm dan dioven pada suhu $100^{\circ} \mathrm{C}$ selama 24 jam. Setelah dioven, bulatan-bulatan kecil tersebut dibakar pada tungku pembakaran selama 3 hari. Pada varisi (variasi KBDSG), tanah diatomae dilakukan perlakuan yang sama seperti diatas, tetapi yang membedakan dari variasi KBD adalah butiran-butiran tanah diatomae dicampur dengan serbuk gergaji berukuran lebih kecil 0,6 mm sebanyak 5\% dari total berat butiran tanah diatomae.

\subsubsection{Perencanaan campuran beton}

Perencanaan campuran beton (mix design) pada penelitian ini berdasarkan ACI 211.2-98 [15]. Komposisi material penyusun beton dihitung juga berdasarkan perkiraan berat volume beton ringan, sehingga sesuai dengan standar untuk beton ringan.

\subsubsection{Pembuatan dan Perawatan Benda Uji}

Pembuatan benda uji dilakukan setelah perencanaan campuran beton selesai dihitung. Materialmaterial pembentuk beton ditimbang sesuai dengan perencanaan(mix design). Masing-masing material seperti agregat kasar, agregat halus, semen, dan air dimasukkan secara berurutan ke dalam molen yang sudah dinyalakan terlebih dahulu. Pengadukan material dilakukan sampai 
adukan homogen dan dilanjutkan dengan pengujian slump. Selama pengadukan material dilakukan penambahan air sedikit demi sedikit karena susah untuk diaduk yang diakibatkan oleh air yang sudah diserap agregat. Jumlah penambahan air pada adukan dicatat.

Pengujian slump dilakukan dengan menggunakan kerucut abrams sesuai dengan ASTM C.143-03[16]. Mortar kemudian dituang kedalam cetakan silinder dalam tiga lapisan. Tiap-tiap lapisan diperkirakan mempunyai volume yang sama. Pada setiap lapisan, mortar dipadatkan sebanyak 25 kali tusukan dengan tongkat besi. Cetakan juga diketuk dengan palu karet agar benda uji menjadi lebih padat. Benda uji dikeluarkan dari cetakan setelah berumur 1 x 24 jam dari waktu pengecoran.

Perawatan dilakukan dengan merendam benda uji dalam bak perendaman selama umur yang direncanakan yaitu 28 hari.

\subsubsection{Pengujian Kuat Tarik Belah Beton}

Kuat tarik belah beton diuji dengan menggunakan mesin uji tekan beton merek Ton Industrie buatan Jerman dengan kapasitas maksimum 100 ton. Benda uji terlebih dahulu dikeluarkan dari bak perendaman tiga hari sebelum pengujian dilakukan agar benda uji dalam keadaan kering. Benda uji kemudian ditimbang beratnya serta diukur dimensinya. Setelah itu, Benda uji diletakkan secara horizontal diantara dua plat pembebanan. Pembebanan tekan diberikan secara merata arah tegak lurus seluruh benda uji hingga benda uji terbelah menjadi dua. Data kuat tarik belah diperoleh dari hasil pemberian beban yang menyebabkan benda uji terbelah menjadi dua.

\subsection{Analisis Data}

Data dari hasil pengujian di laboratorium konstruksi bahan dan bangunan ini kemudian dilakukan pengolah data. Data yang dihasilkan pada penelitian ini berupa data berat isi dan kuat tarik belah setiap benda uji berdasarkan variasi benda uji.

\section{Hasil dan Pembahasan}

\subsection{Hasil}

\subsubsection{Hasil Gradasi Agregat}

Tabel 4 Hasil Gradasi Agregat Variasi KBD

\begin{tabular}{cccc} 
Sieve & $\begin{array}{c}\text { Persentase } \\
\text { Kumulatif agregat } \\
\text { yang Tertahan } \\
\text { Ayakan }\end{array}$ & $\begin{array}{c}\text { Persentase } \\
\text { Kumulatif } \\
\text { agregat yang } \\
\text { Lolos Ayakan }\end{array}$ & $\begin{array}{c}\text { Persentase } \\
\text { Kumulatif agregat } \\
\text { yang Lolos } \\
\text { Ayakan SNI } \\
2461: 2014\end{array}$ \\
\hline$(\mathrm{mm})$ & $(\%)$ & $(\%)$ & $(\%)$ \\
\hline 31,5 & 0,00 & 100,00 & 100 \\
\hline 19,1 & 0,00 & 100,00 & $90-100$ \\
\hline 9,52 & 66,47 & 33,53 & $10-50$ \\
\hline 4,76 & 100,00 & 0,00 & $0-15$ \\
\hline 2,38 & 100,00 & 0,00 & 0 \\
\hline 1,18 & 100,00 & 0,00 & 0 \\
\hline 0,60 & 100,00 & 0,00 & 0 \\
\hline 0,30 & 100,00 & 0,00 & 0 \\
\hline 0,15 & 100,00 & 0,00 & \\
\hline
\end{tabular}

Tabel 5 Hasil Gradasi Agregat variasi KBDSG

$\begin{array}{cccc} & \text { Persentase } & \text { Persentase } & \text { Persentase } \\ \text { Sieve } & \text { Kumulatif } & \text { Kumulatif } & \text { Kumulatif agregat } \\ \text { Size } & \text { agregat yang } & \text { agregat yang } & \text { yang Lolos Ayakan } \\ & \text { Tertahan } & \text { Lolos Ayakan } & \text { SNI 2461:2014 } \\ & \text { Ayakan } & & \end{array}$

\begin{tabular}{cccc}
\hline$(\mathrm{mm})$ & $(\%)$ & $(\%)$ & $(\%)$ \\
\hline 31,5 & 0,00 & 100,00 & 100 \\
\hline 19,1 & 0,00 & 100,00 & $90-100$ \\
\hline 9,52 & 87,41 & 12,59 & $10-50$ \\
\hline 4,76 & 100,00 & 0,00 & $0-15$ \\
\hline 2,38 & 100,00 & 0,00 & 0 \\
\hline 1,18 & 100,00 & 0,00 & 0 \\
\hline 0,60 & 100,00 & 0,00 & 0 \\
\hline 0,30 & 100,00 & 0,00 & 0 \\
\hline 0,15 & 100,00 & 0,00 & 0 \\
\hline
\end{tabular}

Tabel 6 Hasil Gradasi Agregat Halus

$\begin{array}{cccc} & \text { Persentase } & \text { Persentase } & \text { Persentase } \\ \text { Sieve } & \text { Kumulatif } & \text { Kumulatif } & \text { Kumulatif agregat } \\ \text { Size } & \text { agregat yang } & \text { Tertahan } & \text { Tertahan Ayakan } \\ & \text { Lolos Ayakan } & \text { Ayakan } & \text { PBI 1971 }\end{array}$

\begin{tabular}{cccc}
\hline$(\mathrm{mm})$ & $(\%)$ & $(\%)$ & $(\%)$ \\
\hline 31,5 & 100 & 0 & - \\
\hline 19,1 & 100 & 0 & - \\
\hline 9,52 & 100 & 0 & - \\
\hline 4,76 & 100 & 0 & - \\
\hline 2,38 & 87,46 & 12,54 & $>10$ \\
\hline 1,18 & 69,82 & 30,18 & - \\
\hline 0,6 & 39,202 & 60,798 & $80-95$ \\
\hline 0,3 & 10,582 & 89,418 & - \\
\hline 0,15 & 5 & 95 & \\
\hline
\end{tabular}

\subsubsection{Hasil Proporsi Campuran Beton}

Tabel 8 Hasil Perencanaan Proporsi Campuran Beton Ringan per $\mathrm{m}^{3}$

\begin{tabular}{|c|c|c|c|}
\hline \multirow{2}{*}{\multicolumn{2}{|c|}{ Material }} & \multicolumn{2}{|c|}{ Berat Material } \\
\hline & & \multicolumn{2}{|c|}{$(\mathrm{kg})$} \\
\hline & Air (netto) & \multicolumn{2}{|c|}{201,722} \\
\hline & Semen & \multicolumn{2}{|c|}{448,271} \\
\hline & arse Aggregate (CA) & \multicolumn{2}{|c|}{623,163} \\
\hline & ne Aggregate (FA) & \multicolumn{2}{|c|}{718,961} \\
\hline \multicolumn{4}{|c|}{$\begin{array}{l}\text { 4.1.3 Hasil Pengujian Beton Segar } \\
\text { Tabel } 9 \text { Hasil Pengujian Slump }\end{array}$} \\
\hline \multirow[t]{2}{*}{ No. } & \multirow[t]{2}{*}{ Identifikasi } & \multicolumn{2}{|c|}{ Variasi Benda Uji } \\
\hline & & KBD & KBDSG \\
\hline 1. & FAS & 0,45 & 0,45 \\
\hline 2. & Semen (kg) & 20,009 & 20,009 \\
\hline 3. & Air $(\mathrm{kg})$ & 9,435 & 8,953 \\
\hline 4. & Coarse Aggregates ( $\mathrm{kg}$ & 27,378 & 23,978 \\
\hline 5. & Fine Aggregates(kg) & 32,084 & 34,733 \\
\hline 6. & Penambahan Air (kg) & 11 & 10,5 \\
\hline 7. & Slump Test (mm) & 300 & 250 \\
\hline
\end{tabular}

\subsubsection{Hasil Berat Isi}

Tabel 10 Data Berat Isi

Variasi Nama Benda Berat Isi Berat Isi Rata-rata




\begin{tabular}{|c|c|c|c|}
\hline & Uji & $\left(\mathrm{kg} / \mathrm{m}^{3}\right)$ & $\left(\mathrm{kg} / \mathrm{m}^{3}\right)$ \\
\hline \multirow{5}{*}{ KBD } & $\mathrm{KBD}_{11}$ & 1878,34 & \multirow{5}{*}{1886,20} \\
\hline & $\mathrm{KBD}_{12}$ & 1887,65 & \\
\hline & $\mathrm{KBD}_{13}$ & 1886,43 & \\
\hline & $\mathrm{KBD}_{14}$ & 1903,79 & \\
\hline & $\mathrm{KBD}_{15}$ & 1874,84 & \\
\hline \multirow{5}{*}{ KBDSG } & $\mathrm{KBDSG}_{21}$ & 1827,37 & \multirow{5}{*}{1832,590} \\
\hline & $\mathrm{KBDSG}_{22}$ & 1829,86 & \\
\hline & $\mathrm{KBDSG}_{23}$ & 1850,68 & \\
\hline & $\mathrm{KBDSG}_{24}$ & 1833,81 & \\
\hline & $\mathrm{KBDSG}_{25}$ & 1821,22 & \\
\hline
\end{tabular}

4.1.5 Hasil Pengujian Kuat Tarik Belah

Tabel 11 Hasil pengujian kuat tarik belah beton

\begin{tabular}{|c|c|c|c|}
\hline \multirow[t]{2}{*}{ Variasi } & \multirow[t]{2}{*}{$\begin{array}{c}\text { Nama Benda } \\
\text { Uji }\end{array}$} & $\begin{array}{c}\text { Kuat Tarik } \\
\text { Belah }\end{array}$ & $\begin{array}{c}\text { Kuat Tarik Belah } \\
\text { Rata-rata }\end{array}$ \\
\hline & & $\left(\mathrm{N} / \mathrm{mm}^{2}\right)$ & $\left(\mathrm{N} / \mathrm{mm}^{2}\right)$ \\
\hline \multirow{5}{*}{ KBD } & KBD11 & 2,913 & \multirow{5}{*}{3,237} \\
\hline & KBD12 & 3,374 & \\
\hline & KBD13 & 2,967 & \\
\hline & KBD14 & 3,558 & \\
\hline & KBD15 & 3,374 & \\
\hline \multirow{5}{*}{ KBDSG } & KBDSG21 & 2,982 & \multirow{5}{*}{2,992} \\
\hline & KBDSG22 & 3,031 & \\
\hline & KBDSG23 & 3,116 & \\
\hline & KBDSG24 & 3,258 & \\
\hline & KBDSG25 & 2,575 & \\
\hline
\end{tabular}

\subsection{Pembahasan}

Hasil slump test pada Tabel 9 diperoleh nilai slump sebesar 2,5-3,0 cm . Penambahan air terjadi karena pada saat perhitungan mix design, agregat diperhitungkan dalam keadaan saturated surface dry (SSD), sedangkan agregat di lapangan dalam keadaan kering. Pada mix design juga tidak dilakukan perhitungan koreksi air, sehingga agergat dengan absorbsi yang besar akan memerlukan air yang besar untuk diserap ke dalam agregat.

Pada perhitungan berat isi variasi KBD (pada Tabel 10), diperoleh hasil sebesar $1903,79 \mathrm{~kg} / \mathrm{m}^{3}$ $1874,84 \mathrm{~kg} / \mathrm{m}^{3}$ dengan nilai rata-rata $1886,209 \mathrm{~kg} / \mathrm{m}^{3}$. Pada variasi KBDSG, hasil yang diperoleh dalam range $1850,68 \mathrm{~kg} / \mathrm{m}^{3}-1821,22 \mathrm{~kg} / \mathrm{m}^{3}$ dengan nilai rata-rata $1832,590 \mathrm{~kg} / \mathrm{m}^{3}$. Dengan demikian, berat isi variasi KBD sudah mendekati berat isi maksimum untuk beton struktural yaitu $1850 \mathrm{~kg} / \mathrm{mm}^{3}$. Sedangkan pada variasi KBDSG, berat isi sudah memenuhi standar untuk beton ringan struktural.

Hasil pengujian kuat tarik belah variasi KBD pada Tabel 11 diperoleh nilai kuat tarik belah berkisar antara 3,558 $\mathrm{MPa}-2,913 \mathrm{MPa}$ dengan nilai rata-rata kuat tarik belah sebesar 3,237 MPa. Pada beton ringan variasi KBDSG diperoleh nilai kuat tarik belah berkisar antara 3,258 MPa - 2,575 MPa dengan nilai rata-rata kuat tarik belah sebesar 2,992 MPa. Berdasarkan hasil kuat tarik belah beton ringan dari kedua variasi agregat, menurut standar SNI 2461:2014, beton yang dihasilkan dapat dikelompokkan sebagai beton ringan struktural.
ISSN 2685-0605

Hasil kuat tarik belah terbesar diperoleh oleh beton ringan variasi KBD. Hal ini dikarenakan beton variasi KBD memiliki agregat yang lebih padat dibandingkan variasi KBDSG. Variasi KBDSG juga memiliki agregat kasar dengan porositas tinggi sehingga mempengaruhi pada kekuatan beton yang dihasilkan.

Hubungan antara kuat tarik belah dan berat isi beton ringan pada Tabel 12 dan Tabel 13 dapat diplot berupa grafik dalam Gambar 1 dan Gambar 2. Secara umum disimpulkan bahwa semakin besar berat isi beton maka kuat tarik belah akan semakin besar. Beton dengan berat isi rendah ini dapat disebabkan oleh dua faktor yaitu akibat besarnya pori atau jumlah agregat kasar ringan yang banyak. Beton dengan porositas tinggi akan memiliki rongga udara besar, sehingga kepadatan semakin rendah dan menyebabkan kekuatan beton berkurang tetapi mempunyai berat volume yang lebih kecil. Agregat memiliki kontribusi yang besar pada kekuatan beton, jika agregat dengan kekuatan lemah lebih banyak terisi dalam beton maka kuat tarik belah yang dihasilkan juga akan semakin kecil.

Tabel 12 Perbandingan Berat Isi dan Kuat Tarik Belah Variasi KBD

\begin{tabular}{|c|c|c|c|}
\hline \multirow[t]{2}{*}{ Variasi } & \multirow[t]{2}{*}{$\begin{array}{c}\text { Nama Benda } \\
\text { Uji }\end{array}$} & Berat Isi & Kuat Tarik Belah \\
\hline & & $(\mathrm{kg} / \mathrm{m} 3)$ & $\mathrm{MPa}$ \\
\hline \multirow{5}{*}{ KBD } & KBD11 & 1878,336 & 2,913 \\
\hline & KBD12 & 1887,650 & 3,374 \\
\hline & KBD13 & 1886,433 & 2,967 \\
\hline & KBD14 & 1903,789 & 3,558 \\
\hline & KBD15 & 1874,837 & 3,374 \\
\hline
\end{tabular}

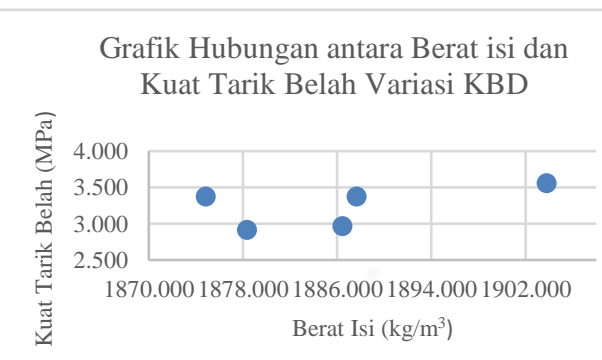

Gambar 1 Grafik hubungan antara berat isi dan kuat tarik belah variasi KBD

Tabel 13 Perbandingan Berat Isi dan Kuat Tarik Belah Variasi KBDSG

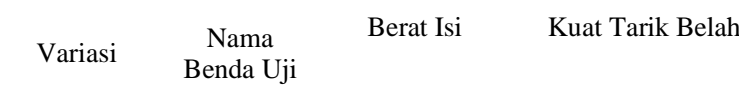

\begin{tabular}{cccc}
\cline { 3 - 4 } & & & \\
& & $(\mathrm{kg} / \mathrm{m} 3)$ & $(\mathrm{MPa})$ \\
\hline \multirow{3}{*}{ KBDSG } & KBDSG21 & 1827,370 & 2,982 \\
\cline { 2 - 4 } & KBDSG22 & 1829,863 & 3,031 \\
\cline { 2 - 4 } & KBDSG23 & 1850,683 & 3,116 \\
\cline { 2 - 4 } & KBDSG24 & 1833,813 & 3,258 \\
\cline { 2 - 4 } & KBDSG25 & 1821,219 & 2,575 \\
\hline
\end{tabular}


Grafik Hubungan antara Berat isi dan Kuat Tarik Belah Variasi KBDSG

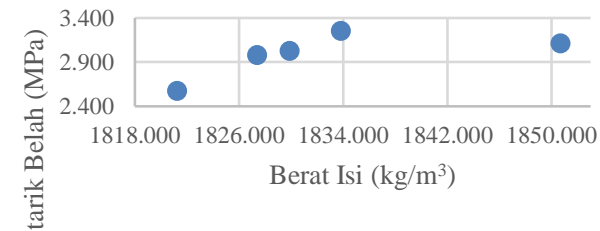

Gambar 2 Grafik hubungan antara berat isi dan kuat tarik belah variasi KBDSG

Tabel 14 Perbandingan Kuat Tarik Belah Terhadap Kuat Tekan Beton Ringan Agregat Kasar Diatomae

\begin{tabular}{cccc}
\hline Variasi & $\begin{array}{c}\text { Kuat Tekan } \\
\text { Rata-rata (Mpa) }\end{array}$ & $\begin{array}{c}\text { Kuat Tarik Belah } \\
\text { Rata-rata (Mpa) }\end{array}$ & $\begin{array}{c}\text { fct/f'c x } \\
100 \%\end{array}$ \\
\cline { 2 - 3 } & (f'c) & (fct) & \\
\hline KBD & 17,599 & 3,237 & 18,393 \\
\hline KBDSG & 15,368 & 2,992 & 19,469 \\
\hline
\end{tabular}

Perbandingan kuat tarik belah dan kuat tekan beton ringan hasil dari penelitian ini disajikan dalam Tabel 14 Nilai kuat tekan beton adalah nilai yang diperoleh oleh teman satu kelompok (Nurul Husna) dimana pengecoran benda uji untuk kuat tekan dan kuat tarik belah dilakukan sekaligus dalam satu molen. Berdasarkan Tabel 14 diperoleh perbandingan nilai kuat tarik belah terhadap kuat tekan beton ringan variasi KBD sebesar 18,393\% dan variasi KBDSG sebesar 19,469\%. Persentase nilai kuat tarik belah terhadap kuat tekan beton ringan sudah melebihi persentase perbandingan kuat tarik belah terhadap kuat tekan beton normal seperti dinyatakan oleh Dipohusodo (1999) sebesar 9\% - 15\%. Sedangkan menurut Park dan Paulay (1975), persentase perbandingan antara kuat tarik belah dan kuat tekan beton normal adalah kurang dari $20 \%$. Hasil kuat tarik belah beton ringan yang lebih besar dari beton normal sesuai dengan hasil Bamforth dan Nolan (2000) yang menyatakan bahwa hal tersebut dapat terjadi pada beton ringan yang memiliki jumlah pasta yang besar, ikatan antar agregat dan pasta yang baik, dan pengaruh pada bentuk agregat yang bulat.

Berdasarkan data kuat tekan yang diperoleh dari pengujian kuat tekan oleh rekan sekelompok, dapat dihitung kuat tarik belah prediksi menurut beberapa persamaan yang diusulkan oleh peneliti terdahulu. Hasil perhitungan kuat tarik belah beton ringan dari kedua variasi dapat dilihat pada Tabel 15 dan Tabel 16, dan perbandingan kuat tarik belah yang didapat dari penelitian ini dengan beberapa persamaan tersebut diperlihatkan pada Gambar 3.

Tabel 15 Perbadandingan Kuat Tarik Belah Variasi KBD dan Peneliti Lain dan Beberapa Standar

\begin{tabular}{cccc}
\hline \multirow{2}{*}{$\begin{array}{c}\text { Nama } \\
\text { Benda } \\
\text { Uji }\end{array}$} & $\begin{array}{c}\text { Kuat Tekan } \\
\text { Rata-rata } \\
(\mathrm{MPa})\end{array}$ & \multicolumn{2}{c}{ Kuat Tarik Belah (Mpa) } \\
\hline & & Hasil Penelitian Ini & 3,237 \\
\cline { 3 - 4 } & & FIP(1983) & 1,806 \\
\cline { 3 - 4 } KBD & 17,599 & ACI 318 (2009) & 1,972 \\
\cline { 3 - 4 } & & $\begin{array}{c}\text { Zherge (1973) } \\
\text { Zhand and Gorv }\end{array}$ & 0,197 \\
\cline { 3 - 4 } & & & 1,806 \\
\end{tabular}

ISSN 2685-0605

\begin{tabular}{ccc}
\multicolumn{3}{c}{ ISSN 2685-0605 } \\
\hline Morales (1990) & 1,762 \\
\cline { 2 - 3 } & Uijl et al, (1995) & 1,624 \\
\cline { 2 - 3 } & $\begin{array}{c}\text { Swamy and Lambert } \\
\text { (1983) }\end{array}$ & 2,169 \\
\hline
\end{tabular}

Tabel 16 Perbandingan Kuat Tarik Belah Variasi KBDSG dan Peneliti Lain dan Beberapa Standar

\begin{tabular}{|c|c|c|c|}
\hline $\begin{array}{c}\text { Nama Benda } \\
\text { Uji }\end{array}$ & $\begin{array}{c}\text { Kuat Tekan } \\
\text { Rata-rata } \\
(\mathrm{MPa})\end{array}$ & \multicolumn{2}{|c|}{ Kuat Tarik Belah (Mpa) } \\
\hline \multirow{8}{*}{ KBDSG } & \multirow{8}{*}{15,368} & Hasil Penelitian Ini & 2,992 \\
\hline & & $\operatorname{FIP}(1983)$ & 1,650 \\
\hline & & ACI 318 (2009) & 1,842 \\
\hline & & Berge (1973) & 0,189 \\
\hline & & $\begin{array}{l}\text { Zhang and Gjorv } \\
\text { (1991) }\end{array}$ & 1,650 \\
\hline & & Morales (1990) & 1,646 \\
\hline & & Uijl et al. (1995) & 1,484 \\
\hline & & $\begin{array}{l}\text { Swamy and Lambert } \\
\text { (1983) }\end{array}$ & 1,989 \\
\hline
\end{tabular}

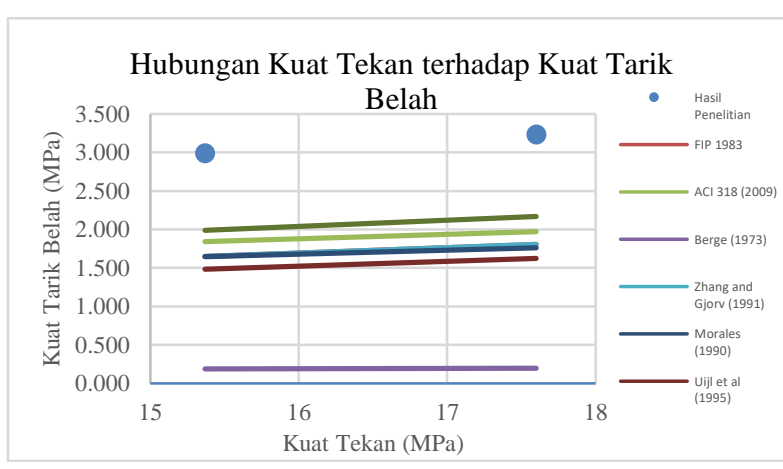

Gambar 3 Grafik hubungan antara kuat tekan dan kuat tarik belah

Berdasarkan Gambar 4.4 kuat tarik belah yang dihasilkan jauh lebih besar dari semua yang didapatkan oleh peneliti lain. Hal ini mungkin disebabkan karena agregat kasar ringan yang digunakan dalam penelitian ini berbentuk bundar sebagaimana dijelaskan oleh Bamforth dan Nolan (2000), sehingga pada saat tegangan ditransfer ke permukaan agregat, maka tegangan tersebut dapat dialihkan ke sekeliling agregat.

\section{Kesimpulan dan Saran}

\subsection{Kesimpulan}

1. Hasil berat isi rata-rata variasi beton ringan KBD adalah $1886,29 \mathrm{~kg} / \mathrm{m}^{3}$ dan berat isi rata-rata variasi beton ringan KBDSG sebesar $1832,590 \mathrm{~kg} / \mathrm{m}^{3}$. Berat isi beton ringan varias KBD sudah mendekati nilai berat isi untuk beton ringan struktural, sedangkan berat isi beton ringan variasi KBDSG sudah memenuhi persyaratan untuk beton ringan struktural.

2. Kuat tarik belah rata-rata pada beton ringan variasi KBD yaitu 3,237 MPa dan nilai kuat tarik rata-rata variasi KBDSG yaitu 2,992 MPa. Beton ringan hasil penelitian ini dapat digolongkan sebagai beton ringan struktural. 
3. Berdasarkan hasil berat isi dan kuat tarik belah, diperoleh hubungan antara keduanya. Secara umum, semakin tinggi nilai berat isi maka kuat tarik belah semakin besar.

4. Persentase kuat tarik belah terhadap kuat tekan beton ringan diperoleh dari hasil penelitian ini melebihi beton normal. Hal ini menurut hasil Bamforth dan Nolan (2000) terjadi pada beton ringan yang memiliki jumlah pasta yang besar, ikatan antara agregat dan pasta yang baik, dan adanya pengaruh bentuk agregat yang bulat.

\subsection{Saran}

1. Pada proses pembuatan agregat diharapkan agregat dibakar pada rotary kiln pada suhu $1000^{\circ} \mathrm{C}$, agar agregat terbakar secara merata sehingga agregat diharapkan akan memiliki kekuatan yang lebih besar.

2. Pada perhitungan mix design diperlukan perhitungan faktor koreksi air bila agregat yang digunakan tidak dalam kondisi SSD, agar pada saat pengecoran diperoleh hasil sesuai dengan perencanaan dan diharapkan dapat meningkatkan mutu beton.

\section{Daftar Pustaka}

[1] Maulani, E., Pemakaian Tanah Diatomae sebagai Substitusi Semen FAS 0,30 dengan Perlakuan Kalsinasi untuk Produksi Beton Normal, Teras Jurnal, 2016.

[2] SNI 03-2847-2002, Tata Cara Perhitungan Struktur Beton untuk Bangunan Gedung, Badan Standarisasi Nasional, Bandung, 2002.

[3] SNI 03-3449-2002, Tata Cara Rencana Pembuatan Campuran Beton Ringan dengan Agregat Ringan, Badan Standarisasi Nasional, Bandung, 2002.

[4] Nugraha, P. dan Antoni, Teknologi Beton (dari Material, Pembuatan, ke Beton Kinerja Tinggi), Penerbit Andi, Yogyakarta, 2007.

[5] SNI 2461:2014, Spesifikasi Agregat Ringan untuk Beton Struktural, Badan Standarisasi Nasional, Jakarta, 2014.

[6] Rahmah, Ramlawati, dan Side, S., "The Adsorption Capacity of Diatomae (Diatomaceous Earth) on Chromium (VI) Ion", Jurnal Chemical, 12(1):60 - 66, 2011.

[7] Benayache, S., Alleg, S., Mebrek, A., Sunol, J. J., Thermal and Microstructural Properties of Paraffin/Diatomite Composite, Elshevier, 2018.

[8] Posi, P., Lertnimoolchai, S., Sata, V., dan Chindaprasirt, P., Pressed Lighweight Concrete Containing Calcined Diatomite Aggregate, Journal of Construction and Building Materials, 47:896-901, 2013.

[9] Fragoulis, D., M.G. Stamatakis, E. Chaniotakis dan G. Columbus, Characterization of Lightweight Aggregates Produced with Clayey Diatomite Rocks Originating from Greece, Journal of Materials Characterization, 53:307316, 2004.

[10] SNI 03-2491-2002, Metode Pengujian Kuat Tarik Belah, Badan Standarisasi Nasional, Bandung, 2002.

\section{ISSN 2685-0605}

[11] SNI 2461:2014, Spesifikasi Agregat Ringan untuk Beton Struktural, Badan Standarisasi Nasional, Jakarta, 2014.

[12] Dipohusodo, I., Struktur Beton Bertulang, Jakarta:PT Gramedia Pustaka Utama, 1999.

[13] Park, R., dan Paulay, T., Reinforce Concrete Structure, John Wiley dan Sons, Newyork, 1975.

[14] Bogas, J. A., dan Nogoueira, R., Tensile Strength of Structural Expanded Clay Lightweight Concrete Subjeted to Different Curing Condition, KSCE Journal of Civil Engineering, 18:1780-1791, 2014.

[15] ACI 211.2-98, Standard Practice for Selecting Proportions for Structural Lightweight Concrete, American Concrete Institute, 1998.

[16] ASTM C.143-03, Test Method Slump of HydraulicCement Concrete, International Standards-Worldwide, 2003. 